\title{
The Relevance of the Economic Environment to the Development and Growth of Academic Spin-Offs. A Panel Approach
}

\author{
Ivano De Turi ${ }^{1,2}, \&$ Margaret Antonicelli ${ }^{2}$ \\ ${ }^{1}$ Lum Jean Monnet University, Bari, Italy \\ ${ }^{2}$ School of Management, Lum Jean Monnet University, Bari, Italy \\ Correspondence: Ivano De Turi Lum Jean Monnet University, Casamassima (Bari), Italy, SS. 100 km 18, Italy.
}

Received: June 3, 2020

doi:10.5539/ibr.v13n8p56
Accepted: July 3, 2020

Online Published: July 21, 2020

URL: https://doi.org/10.5539/ibr.v13n8p56

\begin{abstract}
The importance of academic research ("AR") to economic growth is widely accepted but quantification of incremental impacts, and their attribution to any one country's expenditures, is difficult. Yet quantitative justification of government AR funding is highly desirable. We therefore attempt to quantify one impact which can be directly and causally attributed to one country's funding: spin-off companies.

Although there is great interest in the new knowledge economy, less favoured regions seem permanently disadvantaged because they lack a critical mass of knowledge capital to initiate accumulation, growth and economic development processes. This is a problem for policy-makers seeking to promote economic growth and territorial cohesion in such regions. This paper seeks to develop four empirical models of how Academic spin-off companies can improve their economic performances. The economic benefits that such companies bring are explored, to identify those elements which can potentially upgrade regional economies through knowledge accumulation, which are termed 'building up territorial knowledge pools'.
\end{abstract}

We argue that the impacts of valid and ongoing policies in support of the Third Mission represent incremental contributions to the ROI of academic spin-offs, much greater (also on a updated base). The impacts therefore provide a quantitative justification for public investment, allowing much more important (but less quantifiable) long-term benefits be considered as a "free" bonus.

Keywords: innovation, entrepeneurship, technology transfer, econometric approach, panel model, academic spin-off

\section{Introduction}

\subsection{Introduce the Problem}

The pursuit of territorial development goals is strongly anchored to the ability to create, by the institutions present, a fertile environment for contamination between public and private bodies with the same purpose: territorial competitiveness. The scientific contributions drawn up on the connection among technology transfer, entrepreneurship and territorial competitiveness date back to the late 1980s. In this context, several publications have been developed concerning the National Innovation System (Lundvall, 1992). The concept of the National Innovation System is based on the premise that understanding the links between the actors involved in innovation is the key to improving technology performance. Innovation and technical progress are the result of a complex set of relationships between the actors who produce, distribute and apply various types of knowledge. Participation in innovation networks helps research institutions and universities to obtain funding, improve their position and expand their professional networks, while providing participating academic staff with opportunities for further qualifications (Shultz et al., 2018). The innovative performance of a country depends, largely, on how these actors relate to each other, as elements of a collective system of knowledge creation and use, as well as the technologies they use. These actors are mainly private companies, universities and public research institutes and the people within them. The links can take the form of joint research, staff exchanges, crosspatenting, purchase of equipment and a variety of other channels. There is no single accepted definition of the National Innovation System (OECD, 1997). Innovation is a systemic process, no company innovates without the need to share certain elements of its innovation. It does so, therefore, in collaboration and interdependence with other subjects that can be both businesses (suppliers, customers, partners, etc.) and subjects other than businesses (universities, public 
bodies, non-profit organizations, etc.). The policies implemented in recent years have tried to accompany these processes of change towards models of smart communities. The dialogue between administrations and public and private bodies in charge of industrial policies and policies for R\&D and innovation (MIUR, MISE, first of all), as reported in many studies, has become essential. This need is increasingly leading to experimenting models of collaborations and consultations, in line with the objectives set EU.

\subsection{State Hypothesy and the Correspondence to Research Design}

The importance of academic research ("AR") to long-term economic growth is widely accepted but difficult to quantify. Demonstrating causal connections and incrementality is challenging, and the often-long delays between basic research and substantial commercialization exacerbate the problems.

AR creates other very important but usually less spectacular impacts that do clearly require national investments in AR, and go to the heart of critically important national capabilities: to absorb outside knowledge, to inspire and educate the next generation, to benefit from technological spillovers (Salter and Martin, 2001), to encourage private R\&D (Jaffe, 1989), and to create new companies and vibrant intellectual and economic communities. These imply strongly that basic research is crucial for the strategic position of a nation in the world economy and that "no nation can free ride on the world scientific system". Nonetheless, while these benefits are almost certainly very large, it is usually very hard to say how larg.

Rather than studying AR's largest impacts, we investigate an impact that can be attributed to a single firm, is quantifiable, has a clear causal connection to AR, and which can be argued to be incremental: companies spun-off to directly exploit universitycreated IP based on science or technology. Such impacts represent only a fraction of AR's benefits but, if they significantly exceed the government funding, they may single-handedly justify it.

Based on statements like these just reported, actually to the research hypothesis, the present study will develop on the following hypothesis:

H1: the policies in support of the Third Mission have a positive and statistically significant impact on the ROI, a variable dependent on the models that will subsequently be performed.

\section{What Can Be the Triggers to Feed Innovative Entrepreneurship Processes?}

The relationships that are created between innovation players at local, regional and national levels contribute to the creation of a profitable environmental context for the indirect improvement of business performance. Feeding the national and regional innovation system represents a perfect solution to implement the innovation network and multiply its fruits in terms of transversal benefits to businesses in the area. Among the first objectives is the spread of an 'entrepreneurial culture' (Keats and Abercrombie, 1991) which has also induced the university world to support this rediscovered interest, requiring an in-depth research activity on the factors that lead to becoming entrepreneurs and on how to convey these entrepreneurial characteristics (Alberti, 1999). A condition that facilitates the sustainability of any business project is given by the innovativeness of the product / service offered or the proposed process. Innovation refers to a company's efforts to find new opportunities and new solutions. It involves creativity and experimentation, which translate into new products, new services or improved technological processes. Innovation is one of the main components of an entrepreneurial strategy. The task of managing innovation, however, can be quite stimulating. Innovation requires that companies move away from existing technologies and practices and go beyond the current state of technology. The entrepreneurial mindset allows individuals to seek opportunities, take risks beyond security, tolerate bankruptcies, creatively exploit resources and overcome obstacles to push an idea to realization (Morris, Kuratko, 2014). As Fetters, Greene, Rice and Butler (2010) recall, universities are at the center of economic development around the world, providing infrastructure, resources and means to develop business communities. They also believe that entrepreneurial ecosystems evolve and expand through the specialization of knowledge and innovation. According to Aulet (2008), the relevant aspects of entrepreneurship ecosystems are the alignment of institutional objectives, access to universities and other regional resources, the coordination of research initiatives and the participation of the business community and local government. They suggest that the necessary dimensions of an entrepreneurial system are governance, innovation, infrastructure and culture. In addition, the experiential nature of many entrepreneurship programs attracts students interested in real world involvement rather than lesson-based classroom education (Antal et al., 2014).

\subsection{The University Third Mission as Accelerator of Innovation Processes for SMEs}

The idea that scientific research is central to economic and social development is certainly not new. However, what appears clear as a central address at university level (Anvur, 2013) is the driving role that each university is 
called to play on its territory: universities, in addition to producing new knowledge, must take on a more direct and entrepreneurial role (Etzkowitz, 2008). In the Anglo-Saxon world, the relationships between universities and industry are intense and well structured, with strategic alliances based on solid foundations and cultivated by a proactive behavior of university structures. In continental Europe, on the contrary, these relations appear very weak and in many cases non-existent. This has prompted the European Union to encourage the development of a university "third mission", oriented to the projection of scientific research in the industrial context and its enhancement through tools aimed at the technological transfer of innovation. We could interpret this "third mission" as a role of service to society, with implications in three areas of application (Montesinos, 2008). A first based on the ability to create internally interesting innovations for specific industrial sectors, with more defined application purposes. A second linked to the offer of services with high value added to the community, supporting students and researchers in the delicate work of disseminating their research results in concrete application contexts (businesses and public administrations). Finally, a third connected to the university's entrepreneurial role, which activates professional consultancy and mentoring services for the birth of newco (academic start-ups and spin-offs) or for the acceleration of their development. An "entrepreneurial university" builds a privileged ground for initiating an all-round dialogue with the political and entrepreneurial world to direct progress towards more fruitful terrains, in line with the resources and skills of a given territory. A university that balances theoretical knowledge and business practices in a technology transfer mechanism driven by entrepreneurship (Garzoni, 2014). In recent years, greater attention has been paid by universities to Third Mission activities and, in particular, there has been an increase in third party contracts, patents granted, spin-o accredited companies and other Third Mission activities.

\subsection{Technology Transfer as a Third Mission Tool}

Universities also differ on the basis of their ability to monetize research results through the establishment and maintenance of relations with businesses also through technology transfer activities. A fundamental vehicle of technology transfer has always been constituted by direct relations between universities and businesses, built around joint research projects or contract financing of academic research (Balconi et al., 2002). The term Technology Transfer (TT) is intended to define the process of converting scientific discoveries into products and processes that companies can market. The general concept of technology transfer and commercialization is defined as "activities and processes to create added value through the transfer, exchange, expansion and application of technologies developed from the point of view of technological innovation throughout the period" (Koo, 2014). Various resources are needed to conduct research and development. Since one of the factors considered as a source of competitive advantage is innovation through technology, investing in research and development is a strategically important decision-making process (Lee and Yang, 2015). Support for innovation and technology transfer was mainly provided through the granting of research and innovation funding (both with national and regional laws) and through the creation and support of centers for TT, generally created with the support of regional bodies and other public and private actors. To understand how universities or research centers can become effective partners in supporting the competitiveness of the industrial system, one must consider the fact that in companies the innovation process is generated, in the majority of cases, by the perception of a competitiveness differential on the market, which will require interventions in the company to maintain an advantageous position or to bridge the gap with its competitors. If this factor derives from commercial aspects, the innovation will, in all probability, affect the processes, organization and sales networks. Sometimes, however, the determining factor is of a technological nature and requires companies to take a path to generate or acquire knowledge or technologies and to make them profitable. This path, at least in part, can be guided. Technologies, methodologies and their transfer often represent the main structure of these processes. Some of them can guide innovation by placing themselves along the trajectories of the process, others can enable this process by distributing themselves transversely to multiple processes. In summary, the technology transfer process can be schematized as illustrated in the following figure (Campodall'Orto, Vercesi, 2002).

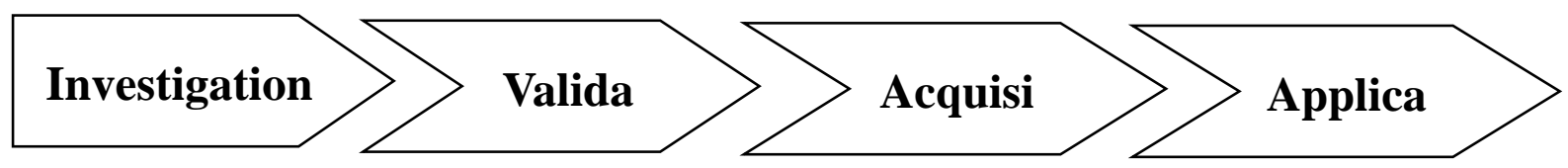

Figure 1. The technology transfer process (Campodall'Orto, Vercesi, 2002) 
The process schematization follows 4 main steps that start from the investigation of the information available. Once the information has been collected, the potential strategic value that it can have in relation to its objectives is identified. In the next step we move on to the "acquisition" phase where the information deemed useful for the innovative process is assimilated and finally we will move on to the "application" phase where the organization applies the technological solutions and methodologies to obtain its competitive advantage. The application is substantiated, in many cases, with the creation of academic spinoffs. The EPR through their offices in charge of technology transfer have set up activities and structures to support the path of creation of new businesses. The growing interest in this phenomenon both from the universities that implement them and from governments that, through the issue of ad hoc measures, seek to incentivize them, finds its foundation in the importance they play in the economic and non-economic spheres. Like all entrepreneurial initiatives, spin-offs promote economic development through the creation of new jobs, as well as being able to attract investments in innovative technologies and to favor their development and application. Furthermore, the creation of spin-offs guarantees an innovation deriving from businesses created on the basis of the results of scientific research and therefore oriented towards the improvement of processes, products and services. Technology transfer management has been defined differently by different academics and professionals. Some consider it the way in which organizations' physical, financial and human resources are integrated into reliable work systems to achieve specific objectives (Osman-Ghani, 1993). This definition is complete as it includes knowledge transfer. Others prefer to separate between technology transfer and knowledge transfer. They argue that technology refers more to tools, methods, processes and products (Sen and Rubenstein, 1989) and therefore is a tangible tool that can influence economic results if used properly and efficiently.

\subsection{The Role of Academic Spin-Offs as Engine for Innovation}

Considering what has been expressed in the previous paragraph, it is clear how relevant the management of such an important process as technology transfer is. University institutes (business incubators, technology parks, TTOs, etc.) dedicated to supporting the spin-offs also have the task of transferring the necessary skills to the teams for managing the TT processes as well as feeding the environmental context to the of which the spin-offs are created also favoring their performances. The exploitation of the results of scientific research in the business world occurs mainly through the establishment of academic spinoffs. Through these tools, universities can play a role in creating qualified job opportunities and economic wealth linked to highly innovative activities. The opportunities related to this tool are many, from the creation of a network or cluster of companies connected to the University (opportunities for collaborations and research contracts) to a useful contribution to the development of the territory. So the university becomes a "knowledge factory", a factory specializing in human capital, a factory dedicated to technology transfer, as well as a factory with a territorial development mission, through the promotion and management of projects for territorial innovation (Lazzeroni \& Piccaluga, 2003). Technology entrepreneurship implies the creation of new companies that exploit opportunities provided by technological innovation. Fostering technology entrepreneurship has become a major topic for (regional) public policy makers, as a means to release currently unexploited opportunities hidden in individuals, shelved technologies and resource combinations. Researchers in the field of technology entrepreneurship have conducted detailed studies of, for example, the factors fostering (successful) technology-based university spin-offs (Rothaermel et al., 2007; Shane, 2004), corporate spin-off creation (e.g., Tubke, 2005 “ ; Zahra et al., 2007), spin-off creation from research institutions (e.g., Clarysse et al., 2005; Hindle and Yencken, 2004; Lockett et al., 2005), and the role of science parks and incubators (e.g., Bergek and Norrman, 2008; Lofsten and Lindelof, 2005; Phan et al., 2005).

\section{Empirical Analysis}

\subsection{Sample}

For the selection of the sample of this study, the 1244 academic spin-offs in Italy from 2015 to 2019 were screened. The Italian platform used for research is Spin-off Italy, the only Italian portal containing updated information on the spin-offs. off of Italian public research. Through the portal, it was possible to obtain detailed information on the characteristics of the spin-offs, both at the registry level and at the economic-financial level.

The aim of the project is to highlight entrepreneurship born from the enhancement of research successes. The portal provides a database on the spin-offs of public research containing company name, legal form, university / public research body (from now EPR) of origin, region of origin, sector and various economic-financial indicators. Furthermore, this information was implemented by additional data extracted from the Aida Bureau Van Dijk platform.

For the purposes of econometric research, it was decided to consider only the Italian spin-offs of public research 
currently active; for our final representative sample of the phenomenon of academic spin-offstherefore, from our reference sample, it was necessary to eliminate the companies registered on the dataset as discontinued or in liquidation.

\subsection{Methodology}

In this study it was performed a fixed panel model. When we deal with the issue of longitudinal data we mean a structure like the one illustrated by the matrix in which generally the number of individuals is high, while that relative to the temporal dimension is rather contained. Note that if the assumptions about the variance and covariance matrix $\Omega$ and the constant (if any) respect those of the pooled time series models, they automatically become can be used in this context simply by exchanging indices relating to individuals and time.

Considering the i-th individual, the fixed effects model is configured as follows

$$
\mathrm{y}_{\mathrm{i}}=\alpha_{\mathrm{i}}+\beta \mathrm{x}_{\mathrm{i}}+\varepsilon_{\mathrm{i}}
$$

where yi and $\varepsilon i$ have dimension $(T \times 1)$, xi has dimension $(T \times k)$ and $\beta$ is the vector containing $k$ parameters from to estimate. The peculiarity of this function concerns the constant which is configured as a vector of $\mathrm{T}$ constant elements equal to ai: this characteristic indicates first of all that for each individual only one value has to be estimatedof the constant and that, if $\alpha_{\mathrm{i}} 6=\alpha_{\mathrm{j}}$ for every i $6=\mathrm{j}$, this constant measures the individual effect, i.e. that set specific characteristics of each individual which however remain unchanged over time. In practice, in model there are in all $\mathrm{k}+\mathrm{N}$ parameters to estimate, $\mathrm{k}$ contained in the vector $\beta$ and $\mathrm{N}$ constants for the different ones individuals. These constants represent the characteristic heterogeneity between individuals in the system peculiar to panel data.

By generalizing the function described above, rewriting it in matrix form, it is possible to write

$$
\left[\begin{array}{c}
y_{1} \\
y_{2} \\
\vdots \\
y_{N-1} \\
y_{N}
\end{array}\right]=\left[\begin{array}{ccccc}
\iota_{T} & 0 & \ldots & 0 & X_{1} \\
0 & \iota_{T} & \ldots & 0 & X_{2} \\
\vdots & \vdots & \ddots & \vdots & \vdots \\
0 & 0 & \ldots & 0 & X_{N-1} \\
0 & 0 & \ldots & \iota_{T} & X_{N}
\end{array}\right]\left[\begin{array}{c}
\alpha_{1} \\
\alpha_{2} \\
\vdots \\
\alpha_{N} \\
\beta
\end{array}\right]+\left[\begin{array}{c}
\varepsilon_{1} \\
\varepsilon_{2} \\
\vdots \\
\varepsilon_{N-1} \\
\varepsilon_{N}
\end{array}\right],
$$

where $\mathrm{\imath T}$ is a vector containing $\mathrm{T}$ elements equal to 1 . In compact form we have therefore

$$
Y=\left[\left(I_{N} \otimes \iota_{T}\right) \quad X\right]\left[\begin{array}{l}
\alpha \\
\beta
\end{array}\right]+\varepsilon
$$

or

$$
\underset{(N T \times 1)}{Y}=\underset{(N T \times N)}{\left(I_{N} \otimes \iota_{T}\right)} \underset{(N \times 1)}{\alpha}+\underset{(N T \times k)}{X} \underset{(k \times 1)}{\beta}+\underset{(N T \times 1)}{\varepsilon}
$$

Since the values of the vector $\alpha$ are not observable they would fully enter the error of the model but, if so, they could be correlated with the explanatory variables $\mathrm{Xi}$ and the estimate would result distorted.

This function allows you to estimate the model through the OLS as all the classic hypotheses are respected. The model is called a dummy variable model because it is necessary to construct $\mathrm{N}$ (nuerosity) of individual effects) dummy variables to be inserted within the regressors matrix. The estimator you are gets undistorted, consistent and BLUE. Given that for the properties of the product of Kronecker it holds

$$
(\mathrm{IN} \otimes \imath \mathrm{T})^{\prime}(\mathrm{IN} \otimes \imath \mathrm{T})=\mathrm{IN} \otimes \imath{ }^{\prime} \mathrm{T} \imath \mathrm{T}=\mathrm{T} \mathrm{IN}
$$

it turns out

$$
\left[\begin{array}{c}
\hat{\alpha} \\
\hat{\beta}
\end{array}\right]=\left[\begin{array}{cc}
T I_{N} & \left(I_{N} \otimes \iota_{T}\right)^{\prime} X \\
X^{\prime}\left(I_{N} \otimes \iota_{T}\right) & X^{\prime} X
\end{array}\right]^{-1}\left[\begin{array}{c}
\left(I_{N} \otimes \iota_{T}\right)^{\prime} Y \\
X^{\prime} Y
\end{array}\right]
$$

To invert the matrix contained within the expression of the OLS estimator, a known result is used on partitioned 
matrices and, after some calculations you get to

$$
\left[\begin{array}{c}
\hat{\alpha} \\
\hat{\beta}
\end{array}\right]=\left[\begin{array}{c}
\frac{1}{T}\left(I_{N} \otimes \iota_{T}\right)^{\prime}(Y-X \hat{\beta}) \\
\left(X^{\prime} M X\right)^{-1} X^{\prime} M Y
\end{array}\right],
$$

where $\mathrm{M}=\mathrm{INT}-\mathrm{P}$ is the projection matrix which, applied to a variable, for each individual returns lo deviation from the time arithmetic mean. This matrix, by definition, turns out to be square $(\mathrm{NT} \times \mathrm{NT})$, diagonal block, symmetrical and idempotent.

\subsection{Results and Discussion}

The object of analysis, as well as the dependent variable of our model, is represented by the ROI, by which we mean the profitability and the economic efficiency of the characteristic management regardless of the sources used: that is, it expresses what makes the capital invested in that 'company.

The quantitative variables observed for the econometric model are:

- EMPLOYEES, expresses the average number of employees assigned during the three-year period;

- ASSETS, expressed in thousands of euros the average amount of tangible, intangible and financial fixed assets exploited by the company;

- VALUED_ADDED, expresses in thousands of euros the average down payment of the increase in the value of resources acquired through the performance of the production activity;

- PATENT, indicates the average cash flow deriving from the possession of a patent, software or industrial property right in thousands of euro;

- SHARE_CAPITAL, indicates the average amount of financial resources in thousands of euros compared to the shareholders in favor of the company;

- REVENUE, indicates in thousands of euro the average amount of economic utility that an enterprise achieves in its sales and services;

- EBITDA, gross operating profit expressed in thousands of euros, the income from the operational management of a company excluded from the calculation of the financial decisions and the tax context

- ROE, return on equity capital expressed as a percentage of the ratio between Net Income and Equity;

- PFN, solvency index, expressed in thousands of euros the average amount of the algebraic sum of all corporate financial debt net of cash and cash equivalents and financial assets that can be readily disposed.

The Dummy variables taken into consideration are:

- ZONE, used to indicate the geographical area in which the company is located, it takes on value 1 if it is located in the Islands, 2 in the South, 3 in the Center, 4 if it is located in the North-East and finally 5 in the Northwest;

- SECTOR, used to indicate the economic sector of reference, assumes value 1 in the case the activity is inherent in Agriculture / Fishing, 2 in the case of Industry / Crafts, 3 for Services, 4 for Trade and finally 5 if it operates in Tourism;

- LEGAL_FORM, used to indicate the type of legal form adopted, assumes value 1 in the case of S.r.l or S.r.l with sole shareholder, value 2 in the case of simplified S.r.l, 3 if constituted in the form of S.p.A. o S.p.A. a sole shareholder and finally 4 in the remaining cases (S.C.A.R.L., S.C.A.R.L.P.A, limited liability consortium company, joint stock consortium company, consortium cooperative company).

In the first analysis, we proceeded with the study of descriptive statistics and the correlation matrix. Regarding to the approach, it was decided to insert a classical structure of the descriptive statistics rather than the panel approach which provides for the analysis of different indicators with overall structures (which coincides with what was declared) between and within. This was possible because there were no significant differences among the different approaches. In these analyzes, dichotomous variables were excluded. 
Table 1. Descriptive statistics and correlation matrix

\begin{tabular}{|c|c|c|c|c|c|c|c|c|c|c|c|c|c|c|}
\hline \multicolumn{2}{|c|}{ Variable } & Mean & SD & 1 & 2 & 3 & 4 & 5 & 6 & 7 & 8 & 9 & 10 & 11 \\
\hline 1 & ROI & 1.89 & 3.85 & 1 & & & & & & & & & & \\
\hline 2 & Valued_Added & 142.49 & 7.89 & 0.85 & 1 & & & & & & & & & \\
\hline 3 & EBITDA & 21.35 & 41.31 & 0.87 & 0.90 & 1 & & & & & & & & \\
\hline 4 & Patent & 8.54 & 14.87 & $-0,46$ & -0.39 & -0.62 & 1 & & & & & & & \\
\hline 5 & Third Mission & 2.65 & 8.23 & 0.16 & 0.38 & 0.24 & 0.36 & 1 & & & & & & \\
\hline 6 & ROE & 4.85 & 5.78 & 0.23 & 0.19 & 0.21 & -0.15 & 0.45 & 1 & & & & & \\
\hline 7 & Share_Capital & 37.61 & 2.98 & -0.56 & -0.11 & -0.39 & 0.23 & -0.00 & -0.14 & 1 & & & & \\
\hline 8 & Revenues & 327.30 & 7.22 & 0.26 & 0.85 & 0.61 & 0.12 & 0.13 & 0.06 & 0.15 & 1 & & & \\
\hline 9 & PFN & -17.67 & 24.88 & -0.04 & -0.08 & -0.07 & 0.06 & 0.01 & -0.02 & 0.15 & -0.11 & 1 & & \\
\hline 10 & Employees & 3.62 & 2.97 & 0.01 & 0.66 & 0.31 & 0.28 & 0.14 & 0.04 & 0.41 & 0.78 & 0.04 & 1 & \\
\hline 11 & Assets & 157.88 & 5.82 & -0.54 & -0.08 & -0.08 & 0.89 & 0.00 & -0.18 & 0.73 & 0.31 & 0.19 & 0.59 & 1 \\
\hline
\end{tabular}

Finally, innovation actors in emerging countries now make meaningful contributions to local and global innovation. Despite the endogenous variable PATENT has a very strong negative correlation with ROI, after a series of analyzes and reflections carried out, it was decided not to omit it for research purposes, as the industrial patent right represents for the spin-offs of public research one of the main balance sheet items. But what does this right entail? The industrial patent right is an intangible asset which attributes the exclusive right to use an invention within the time limits established by law; in fact, its entry in the balance sheet assets allows not only to exploit ownership, but at the same time implies the possibility of recovering costs through the exploitation of the patent itself. Two independent variables had to be omitted: EBITDA, VALUE_ADDED. These variables have a correlation very strong with the dependent variable ROI, equal to 0.85 and 0.87 respectively; in fact, their presence could create distortions on the econometric model which would invalidate its correctness. After omitting from the research those variables strongly correlated with the profit generated by the academic spin-offs, the investigation continued with the construction of econometric models in order to analyze in depth the impact exerted by the remaining variables considered. Also in this case, for the purpose of a better understanding of the phenomenon, it was necessary to combine the previously classified variables that had a low presence within the dataset; in fact, their use would have compromised the correctness of the model, creating an alteration in the interpretation of the analysis. In particular, the Sector variable has undergone a substantial change: the sectors that have a lower frequency (Nanotechnology, Cultural Heritage and Aerospace) have been compressed into a single variable called Other; while, the Legal_Form variable now is represented by: Srl and OtherLF (the addition of "LF" was necessary to distinguish it from the Other variable inherent to the sector to which it belongs).

Table 2. Multiple Fixed effect Models

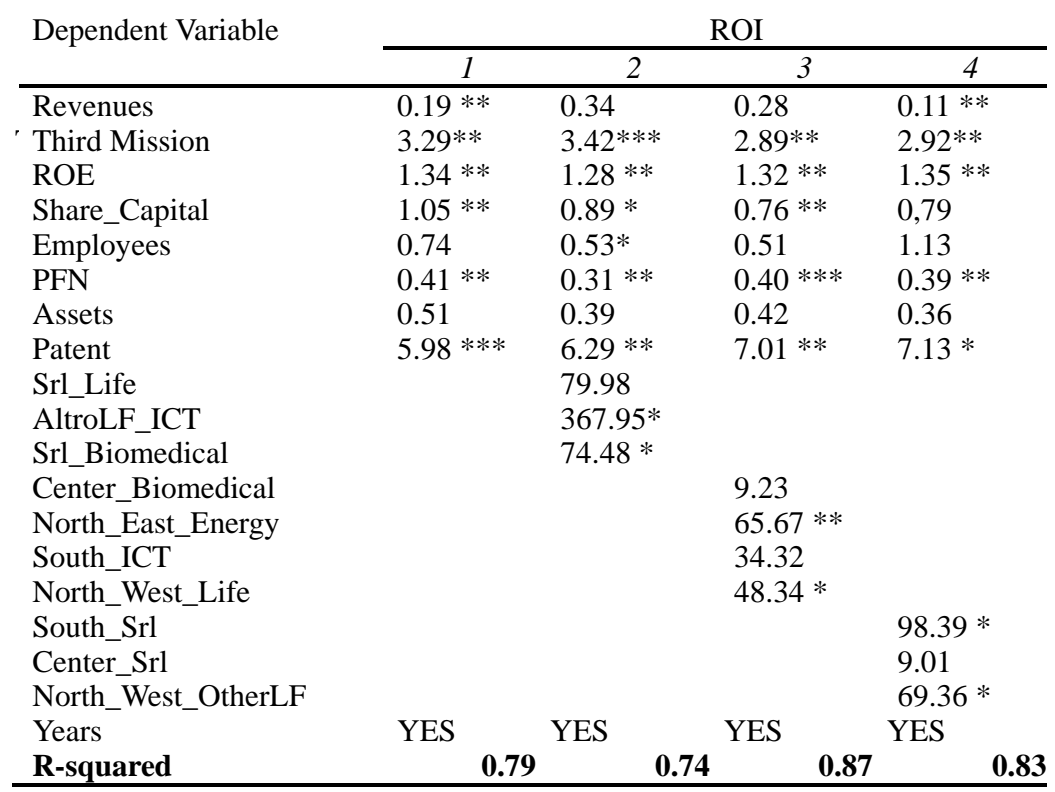


The first econometric model built has the objective of verifying the impact that the different continuous variables have on the dependent variable; in fact, the specific economic and financial characteristics of the academic spin-offs were examined. The analysis shows that the ROI of an academic spin-off increases with the unitary increase in revenues, employees and its net financial position while, conversely, it decreases with the unitary increase in its share capital and costs recorded in the financial statements (Fixed assets and industrial patent law). In this case, the members of the research team not only represent a cost but also an added value for the company as only through their intuition and their genius will it be possible to arrive at a discovery that will increase the profit and return of the spin -off. In addition, the capital endowment is not vital for the continuation of the business activity because (often) the spin-offs are set up on a fixed-term basis to achieve a specific objective. The regression shows an excellent value of the goodness index of the corrected R squared model equal to (0.79). This so high result is probably due to the presence of the Patent variable which, for the reasons already listed, was not omitted from the analysis. Given that the linear variables just observed are re-proposed in the following econometric models, presenting, at the same time, a significance, a sign and an always similar coefficient between the models, it is considered appropriate not to comment further in order to underline only the impact of the new variables examined. From the second multiple regression it is decided to introduce the interaction variables. In particular, in the second econometric model the combined effect exerted by the dichotomous variables Sector and Legal_Form was explored in order to quantify the impact that they jointly exert on the economic-financial performances of the research spin-offs. For this purpose, first of all, investigations were carried out in order to verify which interaction variables reached a level of significance capable of explaining the phenomenon being analyzed. As a result, 3 variables emerged from the searches performed: Srl_Life, OtherLF_ICT and Srl_Biomedical. The following regression highlights two significant variables:

- OtherLF_ICT, $10 \%$ significant, has a positive relationship with the exogenous variable so that the joint possession of the two characteristics leads on average to a significant increase in the ROI of the spin-off . This very high figure derives from the low presence of companies possessing these requirements and therefore, will no longer be considered later;

- Srl_Biomedical, $10 \%$ significant, has a positive relationship with the dependent variable so that the joint possession of these two characteristics leads on average to an increase in ROI of $(+74.48)$. Also in this case, the companies that present these requirements are not very present in the dataset, which is why this variable will not be considered in the final analysis.

Based on the foregoing, despite the momentary lack of significance, the only variable that will be used in subsequent analyzes is the Srl_Life interaction variable.

Similarly, interaction variables have also been introduced in the third econometric model in order to verify the joint impact generated by the Zone and Sector categorical variables on the study objective of the work. The interaction variables included are: Center_Biomedical, North_East_Energy, South_ICT and North_West_Life.

The analysis showed that only two of the four variables introduced are significant for the purpose of our investigation (North_East_Energy and North_West_Life); in fact, these variables will be reused in subsequent analyzes. While previous research has provided important information on the role of the two interactions Legal_Form and Sector and Zone and Sector, the fourth and final linear model studies the impact that generates the joint effect of the dichotomous variables Legal_Form and Zone on the dependent variable.

The regression line shows that two of the three variables introduced positively affect the average increase in the dependent variable and both have the S.r.l requirement; the third variable (North_West_OtherLF), unlike the two previous ones, has a negative impact on the exogenous variable but, despite its significance, it will be discarded by subsequent analyzes, considering that it is scarcely present in the elaborated dataset. The only variable subject to subsequent analysis is South_Srl.

Regarding to our main independent variable, the policy relating to the Third Mission, it is possible to see how the impact of this variable is always positive and statistically significant in all the models developed, this confirming the fact that these aspects are extremely fundamental for the $\mathrm{m}$ improving the performance of academic spin-offs.

\section{Conclusion}

It is now common wisdom that science and innovation are more internationalized and collaborative than ever before. All stand to gain from global innovation. First, more innovation investments are conducted today than at any other time. Second, through international openness, the potential for global knowledge spillovers are on the rise. Finally, innovation actors in emerging countries now make meaningful contributions to local and global 
innovation.

In this study it was possible to ascertain how important it is to have constant and valid government support that can be found in the policies in support of the Third Mission. this is also evident from the positive impact generated by the Employees variable; in fact, in the spin-offs the employees, or rather the members of the research team, they represent Intellectual Capital, which, if enhanced, is able to represent a real key to success for the company.

Secondly, the results achieved by the research contributed to the understanding of the sectoral dynamics of the spin-offs, with particular regard to the reasons why certain sectors impact more on profit or loss than others. In fact, it has been found that belonging to a more popular and more current sector such as the energy sector, in which large investments are required to reap the fruits of research from the short term, increase the company's profit on average. On the other hand, belonging to sectors such as Life Sciences, in which the research results require a greater period of time to obtain appreciable benefits, on average entails a drop in profit. Therefore, a second success factor for the spin-offs is represented by the choice of the sector to which it belongs.

Thirdly, the results obtained from the analysis make it possible to ascertain how, even in the specific case of the spin-offs of public research, the adoption of the legal form Srl, regardless of the sector and the area in which it is placed, determines an increase on average profit by virtue of its advantageous characteristics for these small companies.

\section{References}

Alberti, F. (1999). La formazione imprenditoriale: Teoria e prospettive diricerca. Liuc Papers n. 65, Serie Piccola e Media Impresa 3.

Antal, N., Kingma, B., Moore, D., \& Streeter, D. (2014). University- Wide Entrepreneurship Education. Emerald Group Publishing Limited. https://doi.org/10.1108/S1048-473620140000024009

Anvur. (2013). La terza missione nelle Università e negli enti di ricerca italiani, documento di lavoro.

Aulet, B. (2008). How to build a successful innovation ecosystem: Education, network and celebrate. Retrieved from Xconomy.

Balconi M., \& De Carlini, I. (2002). Lo sviluppo dei settori ad alta tecnologia nell'area pavese: il ruolo dell'università, Luigi Ponzio, Pavia.

Campodall'Orto, S., \& Vercesi, P. (2002). Deve l'universita occuparsi di trasferimento tecnologico? - Mondo Digitale n. 4.

Debackere, K. (2000). Managing academic R\&D as a business at K.U. Leuven: context, structure and process. $R \& D$ Management, 30(4), 323-328. https://doi.org/10.1111/1467-9310.00186

Etzkowitz, H. (2008). The Triple Helix. University-Industry-Government Innovation in Action, Routledge. https://doi.org/10.4324/9780203929605

Fetters, M. L., Greene, P. G., Rice, M. P., \& Butler, J. S. (2010). The Development of University-Based Entrepreneurship Ecosystems: Global Practices. Edward Elgar Publishing, Cheltenham, UK. https://doi.org/10.4337/9781849805896

Garzoni, A. (2014). L'Università imprenditoriale e il progresso dell'economia reale in Scritti in memoria di Giuseppe Degennaro, Cacucci.

Gilsing, V. A., Elco Van, B., \& A. Georges, L. R. (2010). Policy principles for the creation and success of corporate and academic spin-offs. Technovation, 30(1), 12-23.

https://doi.org/10.1016/j.technovation.2009.07.004

Keats, R., \& Abercrombie, N. (1991). Enterprise Culture, Routledge.

$\mathrm{Ku}$, B. C. (2014). Derivation and empirical analysis of critical factors that facilitate technology transfer and commercialization of research outcome. Asia-Pacific Journal of Business Venturing and Entrepreneurship, 9(5), 69-81.

Lazzeroni, M., \& Piccaluga, A. (2003). Towards the Entrepreneurial University. Local Economy. https://doi.org/10.1080/0269094032000073807

Lee, J. H., \& Yang, J. W. (2015). The creation of rirm competitiveness through R\&D investment: the roles of path dependence and resource characteristics. Journal of Strategic Management, 18(3), 71-96. https://doi.org/10.17786/jsm.2015.18.3.004 
Lockett, A., Siegel, D., Wright, M., \& Ensley, M. D. (2005). The creation of spin-off firms at public research institutions: Managerial and policy implications. Research Policy, 981-93. https://doi.org/10.1016/j.respol.2005.05.010

Lundvall, B. Å. (1992). National Innovation Systems: Towards a Theory of Innovation and Interactive Learning. London, Pinter Publishers. ISBN- 13: 978- 1- 78308- 596- 5.

Montesinos, P., Carot, J. M., Martinex J. M., \& Mora, F. (2008). Third mission ranking for world class universities: beyond teaching and research. Higher Education in Europe, 33(2-3). https://doi.org/10.1080/03797720802254072

Morris, M. H., \& Kuratko, D. F. (2014). Building University 21st Century Entrepreneurship Programs. Emerald Group Publishing Limited. https://doi.org/10.1108/S1048-473620140000024001

O'Gorman, C. (2003). Stimulating high-tech venture creation. $R \& D$ Management, 33(2), 177-187. https://doi.org/10.1111/1467-9310.00291

OECD. (1997). National Innovation Systems, OECD Publications, Paris.

Osman-Gani, A. A. M. (1993). International Transfer of Management Technology within a Multinational Enterprise: A Cross-national Study of Managers' Perceptions. Journal of International Business Studies, 4(3) 615-616.

Rasmussen, E. (2008). Government instruments to support the commercialization of university research: lessons from Canada. Technovation, 28(8), 506-517. https://doi.org/10.1016/j.technovation.2007.12.002

Roberts, E. B., \& Malonet, D. E. (1996). Policies and structures for spinning off new companies from research and development organizations. $R \& D$ Management 26(1), 17-48. https://doi.org/10.1111/j.1467-9310.1996.tb00927.x

Schütz, F., Schroth, F., Muschner, A., \& Schraudner, M. (2018). Defining functional roles for research institutions in helix innovation networks. Journal of Technology Management \& Innovation, 13(4), 47-53. https://doi.org/10.4067/S0718-27242018000400047

Sen, F., \& Rubenstein, A. H. (1989). External technology and inhouse R\&D's facilitative role. Journal of Product Innovation Management, 6(2), 123-138. https://doi.org/10.1111/1540-5885.620123

\section{Copyrights}

Copyright for this article is retained by the author(s), with first publication rights granted to the journal.

This is an open-access article distributed under the terms and conditions of the Creative Commons Attribution license (http://creativecommons.org/licenses/by/4.0/). 